\title{
Rhombus-Inscribed Circular Ring Fractal Array Antenna for Millimeter-Wave 5G Applications
}

\author{
Muhammad Usman Tahir, Umair Rafique $\mathbb{D}^{D}$, and Muhammad Mansoor Ahmed \\ Department of Electrical Engineering, Capital University of Science and Technology, Islamabad, Pakistan \\ Correspondence should be addressed to Umair Rafique; umairrafique.1987@gmail.com
}

Received 13 November 2021; Revised 20 January 2022; Accepted 29 January 2022; Published 22 February 2022

Academic Editor: Mohammad Alibakhshikenari

Copyright (c) 2022 Muhammad Usman Tahir et al. This is an open access article distributed under the Creative Commons Attribution License, which permits unrestricted use, distribution, and reproduction in any medium, provided the original work is properly cited.

A $1 \times 4$ planar fractal array antenna is designed and presented for millimeter-wave 5G applications. The array's top side is made up of a rhombus-inscribed circular ring fractal patch radiator, while the backside is made up of a square notch-loaded partial ground plane. To achieve high gain, a $1 \times 4$ corporate feeding network is used to excite the array elements. The designed array has an overall size of $28 \times 17.75 \mathrm{~mm}^{2}$. From simulations as well as experimental results, it is observed that the designed array offers a wide impedance bandwidth in the frequency range of 22.8-29.2 GHz. Furthermore, a peak gain of $10.7 \mathrm{dBi}$ with a radiation efficiency of $>95 \%$ is observed in the operating bandwidth.

\section{Introduction}

Fifth-generation (5G) communication technology will bring unique features for consumers. It will provide access to users everywhere and will select the best performance among other technologies such as Wireless Fidelity (Wi-Fi) and Wireless Local Area Network (WLAN). The selection of the best performance will not only be based on the throughput but also on the most appropriate metrics depending on the nature of the service. Furthermore, 5G systems will support other services such as the Internet of Things (IoT) by providing an internet connection to a vast number of objects. In addition to this, $5 \mathrm{G}$ systems will also cover services such as vehicle-to-vehicle communication (V2V) and remote health services.

$5 \mathrm{G}$ technology provides extremely high data rates with low latency. To achieve a high data rate, there is a need for large bandwidth, which can be achieved with the use of higher frequency bands [1]. For this purpose, millimeterwave (mm-wave) frequency bands are the best solution to achieve high bandwidth along with a high data rate. The International Telecommunication Union (ITU) allocated a few possible frequency bands in the mm-wave spectra, such as $26 \mathrm{GHz}, 28 \mathrm{GHz}, 38 \mathrm{GHz}$, and $60 \mathrm{GHz}$ [2]. Of these bands, the $26 \mathrm{GHz}(24.25-27.5 \mathrm{GHz})$ and $28 \mathrm{GHz}(26.5-29.5 \mathrm{GHz})$ frequency bands receive the most importance worldwide because they enable the operators to achieve speed, reliability, latency, and capacity. However, the losses are high at these frequencies due to the absorption of oxygen molecules $[3,4]$. To mitigate this problem, high-gain antennas are required, and one of the techniques to enhance gain is to design antenna arrays. In addition, the mm-wave communication systems require compact antenna designs. This demand can be fulfilled with the use of planar antennas because they are small in size and have low fabrication costs, and their integration is easy with portable devices. Furthermore, at mm-wave frequencies, the small wavelength provides an extra advantage for designing compact and efficient antennas for $5 \mathrm{G}$ communication systems. In addition, it is realistic to design antennas that are physically small but electrically large enough to perform efficiently. Previously, many researchers have presented different antenna array designs for $5 \mathrm{G}$ communication systems.

In [5], a design of a $1 \times 8$ antipodal Vivaldi antenna (AVA) array was presented for $5 \mathrm{G}$ applications. The authors described that the AVA array operated from $24.55 \mathrm{GHz}$ to $28.5 \mathrm{GHz}$ and offered a peak gain of $11.32 \mathrm{dBi}$. The same kind of AVA configuration was utilized in [6]. In this design, the 
top and bottom radiation elements were constructed using two different tapered slot configurations. The top radiator had an exponential-shaped curve, while the bottom radiator, connected to the ground plane, had an elliptical-shaped tapered curve. Moreover, a defected ground structure (DGS) was used to enhance isolation between array elements. In [7], a broadband planar array was designed for 5G broadcast applications. The array element was composed of two dipole radiators and a power splitter based on a substrate-integrated cavity (SIC). The dipole elements were placed side by side on both sides of the SIC-based power splitter. Although the presented configuration provides a wide impedance bandwidth from $24 \mathrm{GHz}$ to $29.5 \mathrm{GHz}$ and a gain of $10 \mathrm{dBi}$, due to its complex nature, it can rarely be used in $5 \mathrm{G}$ communication devices. In [8], a dual-hexagonal-shaped $1 \times 4$ planar antenna array was presented for the $28 \mathrm{GHz}$ frequency band. A broadband corporate feeding network was utilized to feed the array elements. Furthermore, conducting vias were placed around the array elements to achieve high isolation. The results showed that the presented array had an impedance bandwidth of $10 \mathrm{GHz}$ in the frequency range of $25-35 \mathrm{GHz}$. The same kinds of configurations were presented in $[9,10]$. In [9], a spiral-shaped radiator with three hexagonal-shaped parasitic elements placed at the backside of the radiators was used to achieve a wide impedance bandwidth in the frequency range of $23.76-42.15 \mathrm{GHz}$ and a gain of $11.5 \mathrm{dBi}$, while in [10], a rhombus-shaped patch radiator with square-shaped parasitic elements was utilized to achieve a bandwidth from $26 \mathrm{GHz}$ to $30.63 \mathrm{GHz}$.

A $1 \times 4$ series-fed elliptical slot-loaded circular patch array for $5 \mathrm{G}$ communication systems was presented in [11]. Due to the use of an elliptical slot within the circular patch, a dualfrequency response at $28 \mathrm{GHz}$ and $38 \mathrm{GHz}$ was achieved. Moreover, the gain values were noted to be $7.6 \mathrm{dBi}$ and $7.21 \mathrm{dBi}$ for both bands. In [12], a bow-tie-like dipole antenna array was presented for $5 \mathrm{G}$ applications. With its compact size, the array had an impedance bandwidth ranging from $23.41 \mathrm{GHz}$ to $33.92 \mathrm{GHz}$. They also presented a snow-flake fractal antenna array in [13] for the $28 \mathrm{GHz}$ frequency band that operates in the frequency range of $25.28-29.04 \mathrm{GHz}$ and has a peak gain of $10.12 \mathrm{dBi}$. In [14], a $1 \times 4$ series-fed linear array was presented for $\mathrm{mm}$-wave applications. The designed array consists of a microstrip feed line and a series of shortcircuited stubs periodically placed on one edge of the microstrip feed line. The presented configuration offered an impedance bandwidth of $21.40 \%$ with a peak gain of $12.18 \mathrm{dBi}$. The authors also realized a $4 \times 4$ two-dimensional (2D) array and observed an impedance bandwidth of $19.15 \%$ and a gain of $18.30 \mathrm{dBi}$ in the center frequencies. Although the designs presented in $[12,13]$ provide wide impedance bandwidth, they are large in size.

In $[15,16]$, hook-like and donut-shaped planar antenna arrays were presented for 5G technology. In [17], a squareframed T-shaped planar array was presented for $5 \mathrm{G}$ communication systems. The ground plane configuration was the same as presented in $[15,16]$. The presented designs were small in size, but they had less impedance bandwidth. In [18], an eight-element nonuniform series-fed dipole array was designed for mm-wave wideband applications. The presented dipole array had an extremely wide impedance bandwidth ranging from $23.3 \mathrm{GHz}$ to $51 \mathrm{GHz}$, but it suffers due to low gain. Recently, some researchers designed antenna arrays using substrate-integrated waveguide (SIW) technology [19-21] and achieved wide bandwidth and high gain, but the complex nature of the designs restricts their use in compact communication devices.

In this paper, a $1 \times 4$ planar fractal antenna array is designed for $5 \mathrm{G} \mathrm{mm}$-wave applications. The main objective of the proposed array is to achieve high gain for $28 \mathrm{GHz} 5 \mathrm{G}$ applications. The single element of the array has a rhombus-inscribed circular ring fractal shape, while a notch-loaded partial ground plane is placed on the bottom side to achieve wide impedance bandwidth. The presented results show that the antenna array operates in the frequency range of $22.8-29.2 \mathrm{GHz}$ and has a peak gain of $10.7 \mathrm{dBi}$. Furthermore, the presented array design is simple in nature and can be fabricated using low fabrication techniques, e.g., chemical etching.

\section{Array Design}

2.1. Single Element. As shown in Figure 1(a), a rhombusinscribed circular ring fractal patch fed using a $50 \Omega$ microstrip feed line is designed on the top side of a dielectric substrate, while the backside consists of a square notchloaded partial ground plane (see Figure 1(b)). A low-loss dielectric substrate, Rogers RT/duroid 5880, having a dielectric constant of 2.2 is being utilized for the antenna design. The thickness of the substrate is chosen to be $0.51 \mathrm{~mm}$. The proposed antenna has the following overall design parameters: $W_{S U B}=7, L_{S U B}=7.5, R_{1}=2.6, R_{2}=1.5$, $L_{1}=3.6, L_{2}=1.6, L_{F}=2, W_{F}=1.4, L_{G}=1.6, G=0.5$, and $S=0.25$ (all dimensions are in $\mathrm{mm}$ ).

The design evolution of a single antenna element consists of four major steps, as illustrated in Figure 2. The iteration-1 design consists of a circular ring patch radiator fed using a $50 \Omega$ microstrip feed line, while a notch-loaded partial ground is designed on the bottom side, as shown in Figure 2(a). The dimensions of the circular ring are calculated using the design expressions described in [22]. In iteration-2, a rhombus shape is designed within the circular ring without changing the other dimensions, as shown in Figure 2(b). In iteration-3 and iteration-4, another circular ring and rhombus are designed, as depicted in Figures 2(c) and $2(\mathrm{~d})$.

Figure 3 depicts reflection coefficient $\left(S_{11}\right)$ characteristics for each iteration presented above. It is observed from the result of Figure 3 that the iteration-1 design offered an impedance bandwidth of $4.44 \mathrm{GHz}(25.98-30.42 \mathrm{GHz})$. With every step, the bandwidth of the antenna is improving. Although iteration-2 and -3 designs provide better impedance matching, they have less bandwidth compared to iteration-4 design. The observed impedance bandwidth of the proposed design is equal to $10.72 \mathrm{GHz}(22.28-33 \mathrm{GHz})$.

Figure 4(a) shows the simulated radiation properties of a single antenna element. From the figure, one can observe that the proposed antenna exhibits a bidirectional radiation pattern for the $y z$-plane and a quasi-omnidirectional pattern 


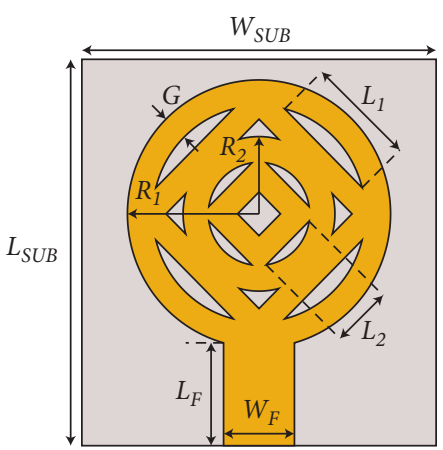

(a)

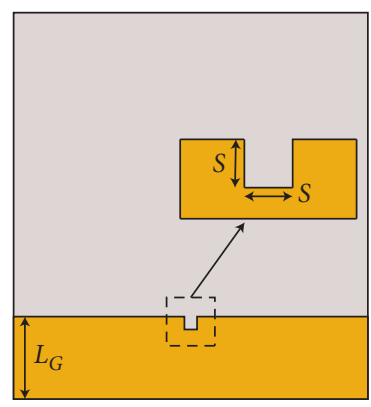

(b)

FIgURE 1: Schematic of the proposed fractal antenna: (a) front side; (b) back side.

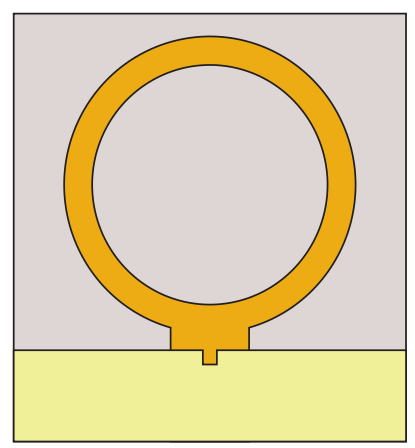

(a)

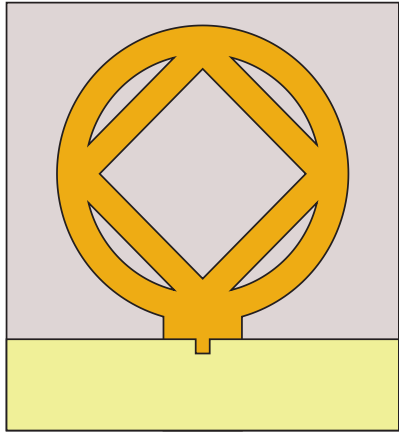

(b)

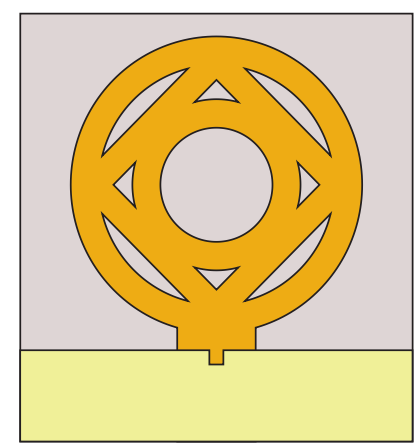

(c)

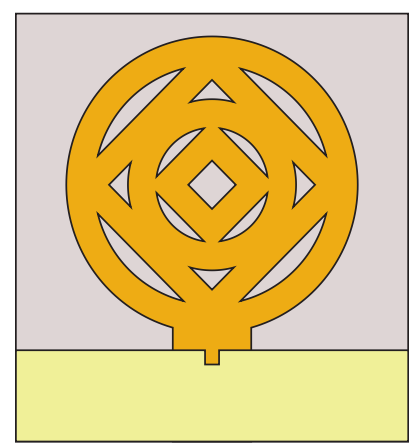

(d)

Figure 2: Design evolution of the proposed fractal antenna: (a) iteration-1; (b) iteration-2; (c) iteration-3; (d) iteration-4 (proposed design).

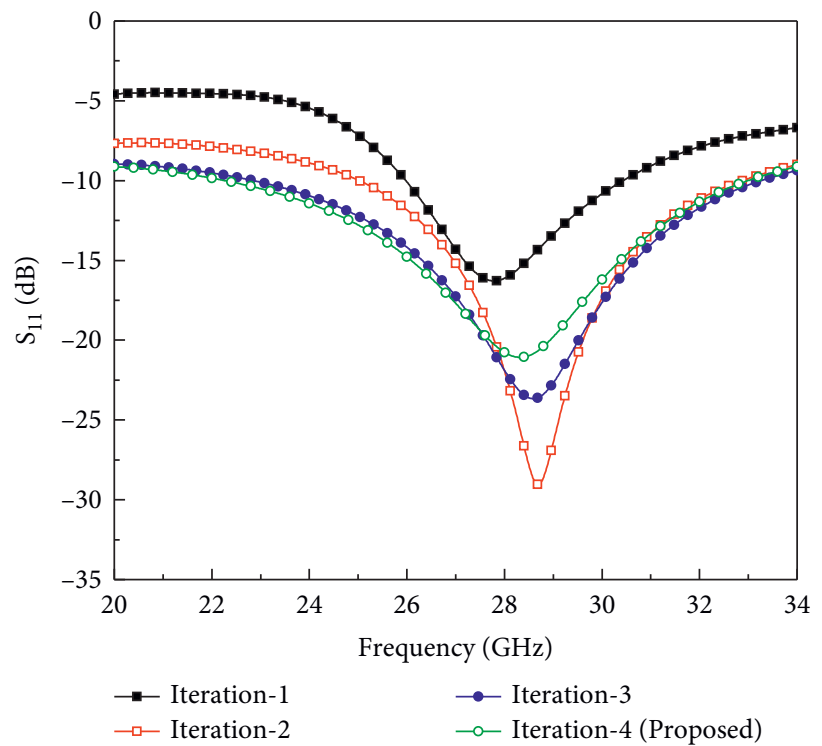

FIgURE 3: Simulated $S_{11}$ for each iteration presented in Figure 2.

for the $x z$-plane. The simulated gain, radiation efficiency, and total efficiency of a single antenna element are illustrated in Figure 4(b). The gain of the antenna varies in the range of $3.5-4.5 \mathrm{dBi}$ within the operating frequency range. Furthermore, the observed radiation and total efficiencies are $\geq 90 \%$ and $>80 \%$, respectively.
2.2. Design of a $1 \times 4$ Antenna Array. To achieve high gain and narrow beamwidth, one of the requirements of $5 \mathrm{G}$ communication systems, a $1 \times 4$ linear array is designed, as shown in Figure 5. For array elements' feeding, a $1: 4$ conventional corporate feeding network is utilized, as shown in Figure 5. The corporate feeding network is designed using 


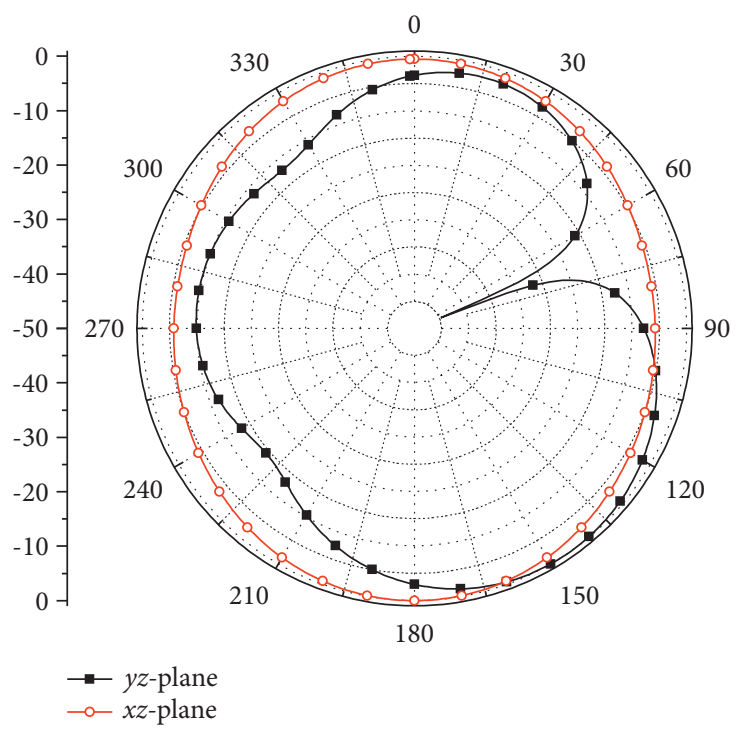

(a)

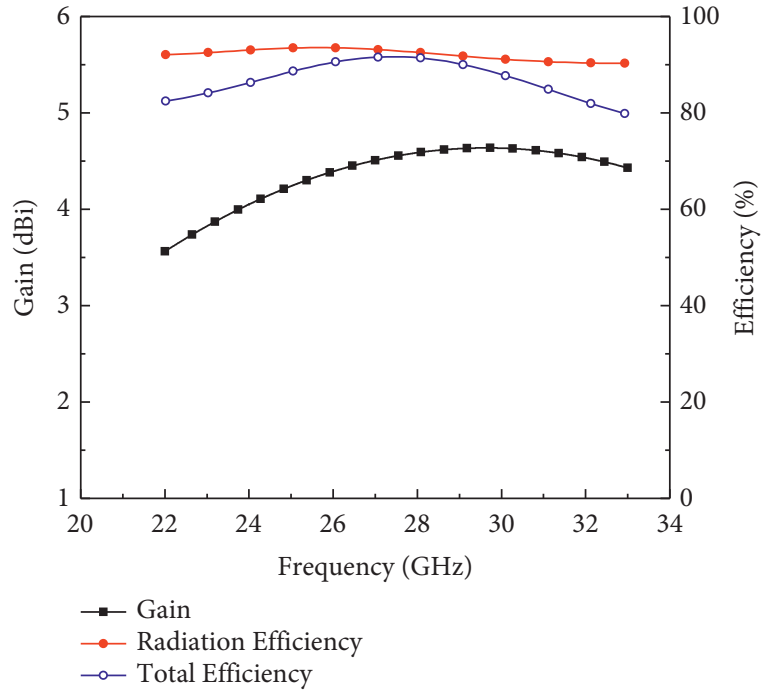

(b)

Figure 4: Simulated (a) radiation characteristics, (b) gain, radiation efficiency, and total efficiency of the proposed fractal antenna.

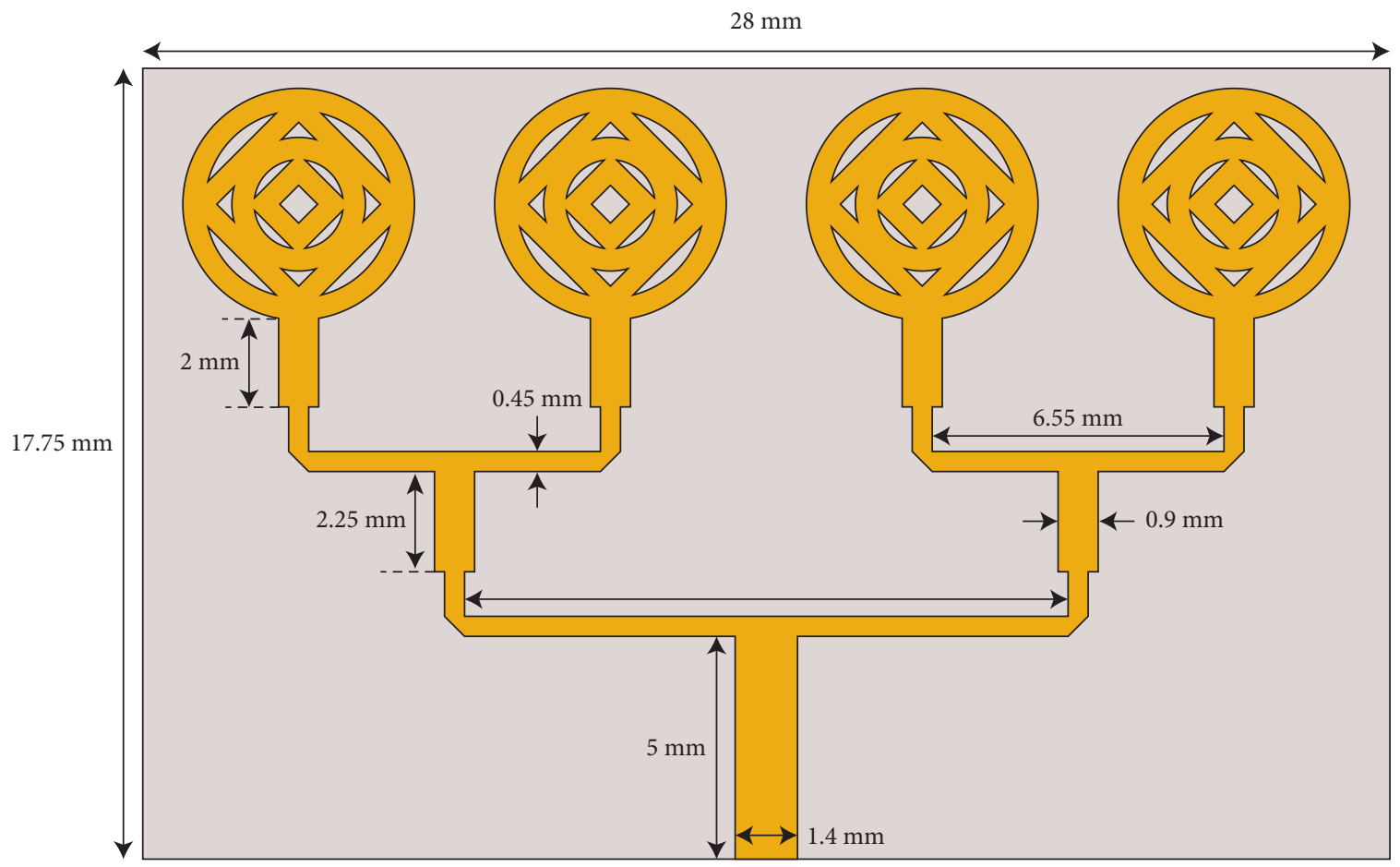

(a)

Figure 5: Continued. 


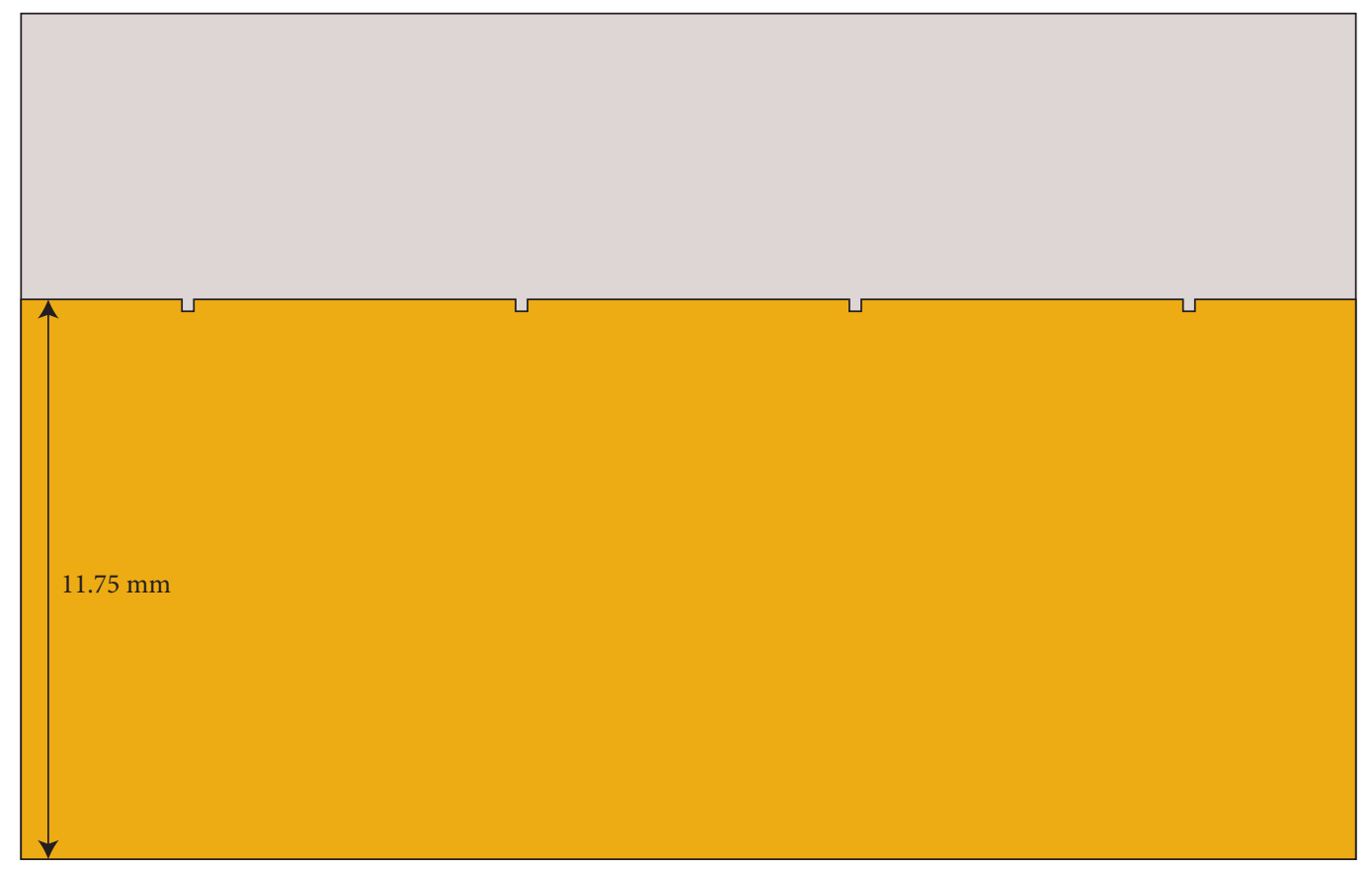

(b)

FIgURE 5: Design of the proposed $1 \times 4$ linear antenna array: (a) front view; (b) back view.

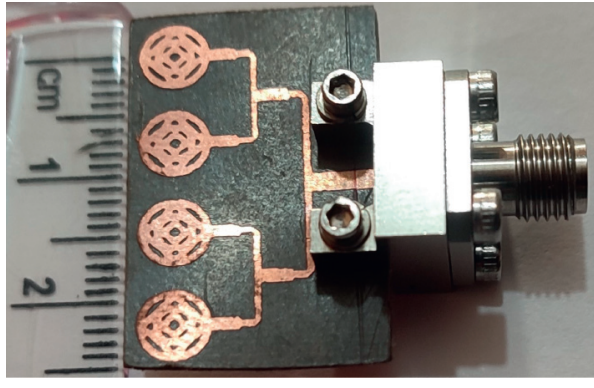

(a)

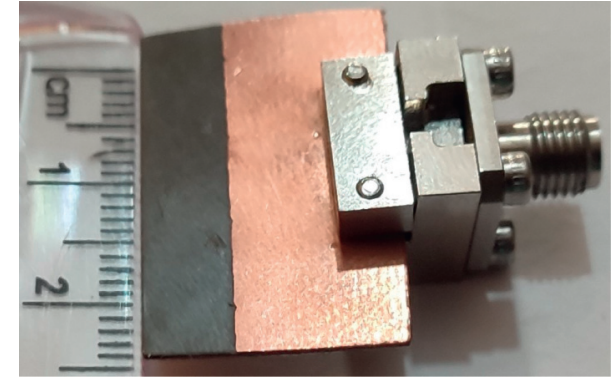

(b)

FIgURE 6: Fabricated prototype of the proposed array: (a) front view; (b) back view.

the design procedure presented in [17]. For better isolation, the distance between the array elements is chosen to be $7 \mathrm{~mm}$, which is greater than $\lambda_{0} / 2$ at $28 \mathrm{GHz}$, where $\lambda_{0}$ is the free-space wavelength.

The proposed four-element linear antenna array is designed and simulated in CST Microwave Studio and manufactured on a Rogers RT/duroid 5880 substrate with a thickness of $0.51 \mathrm{~mm}$. The fabricated array prototype is shown in Figure 6. For measurement purposes, a $2.92 \mathrm{~mm}$ End Launch Screw-on type RF connector from Cinch Connectivity Solutions is used, as shown in Figure 6. For the validation of simulations, the fabricated prototype is measured using the Precision Network Analyzer (PNA) E8363C by Agilent Technologies.

The simulated and measured $S_{11}$ characteristics of the antenna array are shown in Figure 7. From simulations, it is observed that, according to $-10 \mathrm{~dB}$ bandwidth criteria, the designed array operates from $22.92 \mathrm{GHz}$ to $29 \mathrm{GHz}$, while the measurements show that the proposed array resonates in the frequency range of 22.8-29.2 GHz. Moreover, measured $S_{11}$ is in good agreement with the simulated one.

For far-field measurements, the proposed array is characterized in an anechoic chamber using a conventional approach. The block representation of the measurement setup is shown in Figure 8. The proposed array is placed horizontally on a turntable on the opposite side of a horn antenna (reference antenna) having a frequency range of $15-40 \mathrm{GHz}$. To provide a reflection-free environment, the anechoic chamber walls are covered with radio frequency (RF) absorbers, as shown in Figure 8.

The gain of the proposed array is depicted in Figure 9(a), while the radiation efficiency is illustrated in Figure 9(b). Simulations show that the average gain of the proposed array is $\approx 10.3 \mathrm{dBi}$, while the measured gain has an average value of $10 \mathrm{dBi}$, as shown in Figure 9(a). Furthermore, as shown in Figure 9(b), the simulated and measured radiation efficiency 


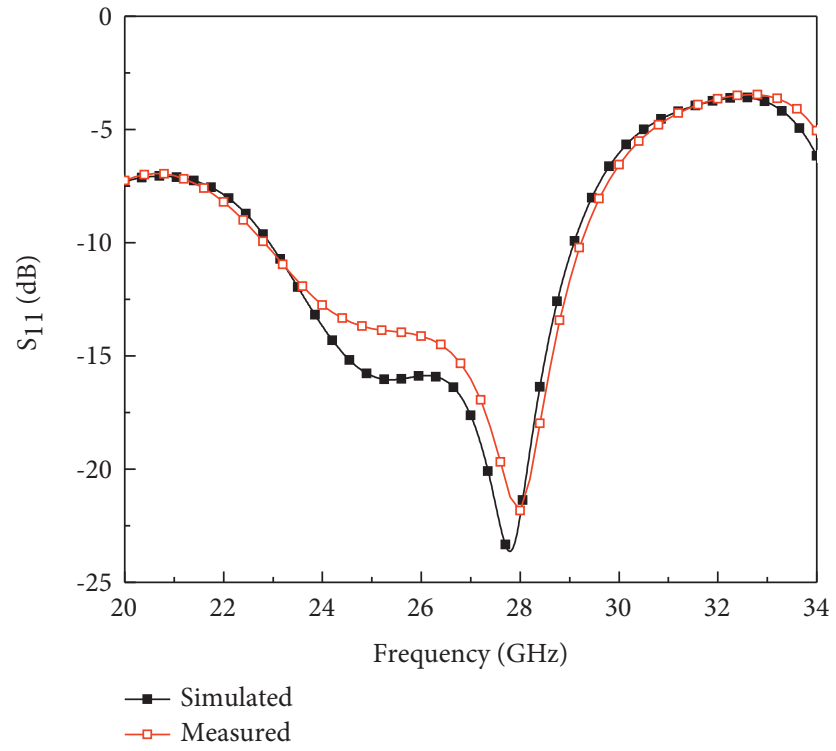

FIGURE 7: $S_{11}$ characteristics of the proposed array.

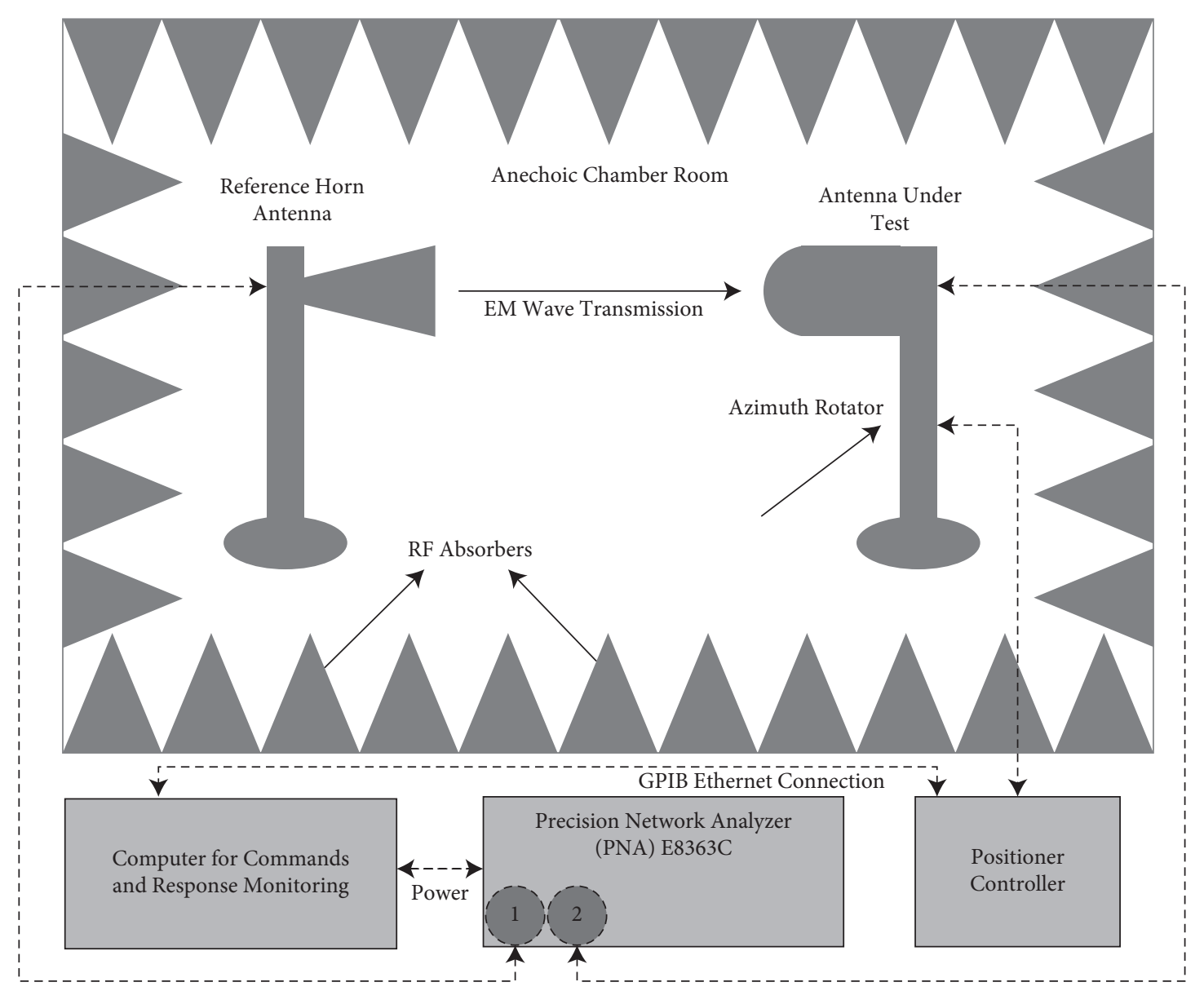

FIGURE 8: Block representation of the far-field measurement setup. 


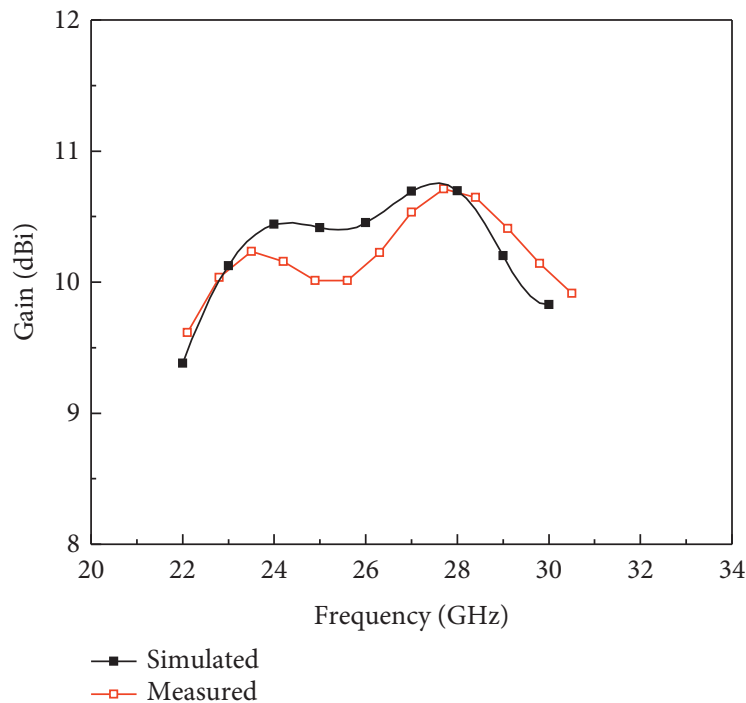

(a)

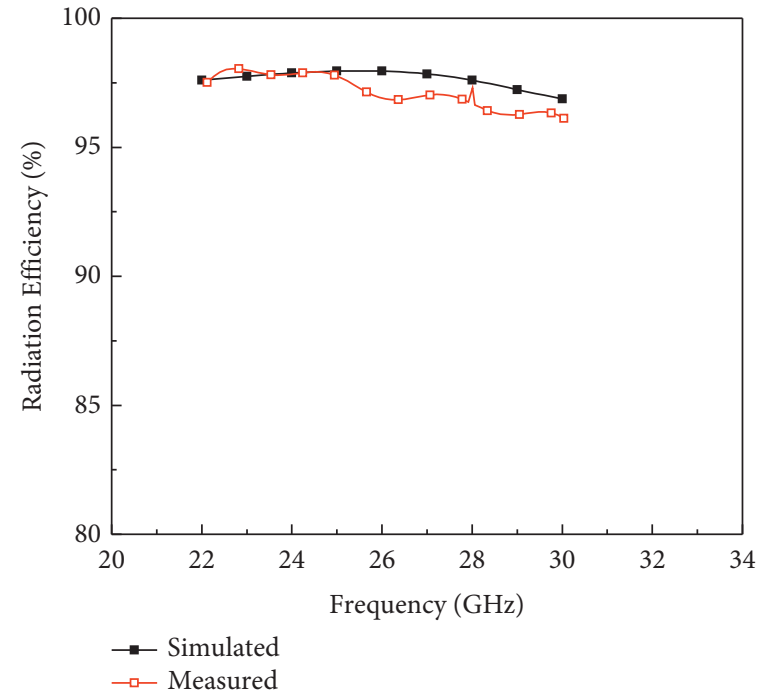

(b)

FIGURE 9: Simulated and measured (a) gain and (b) radiation efficiency of the proposed array.

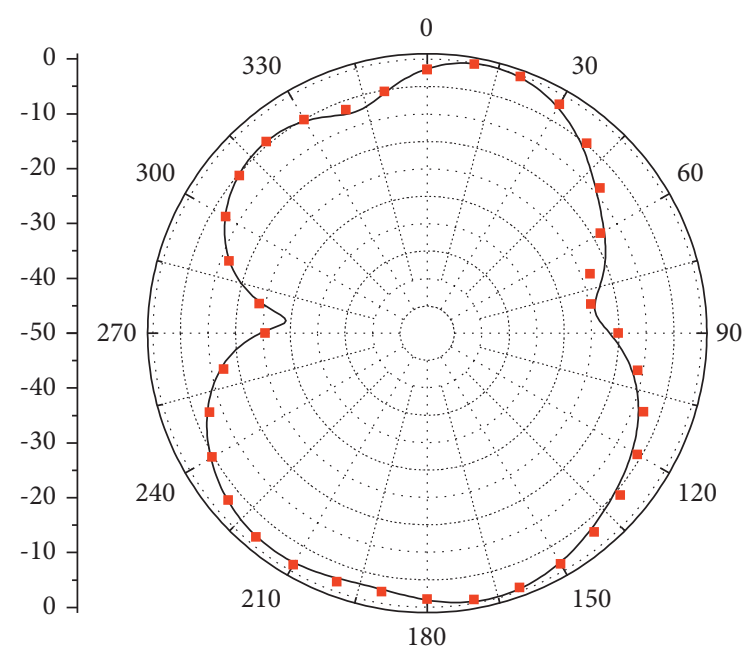

(a)

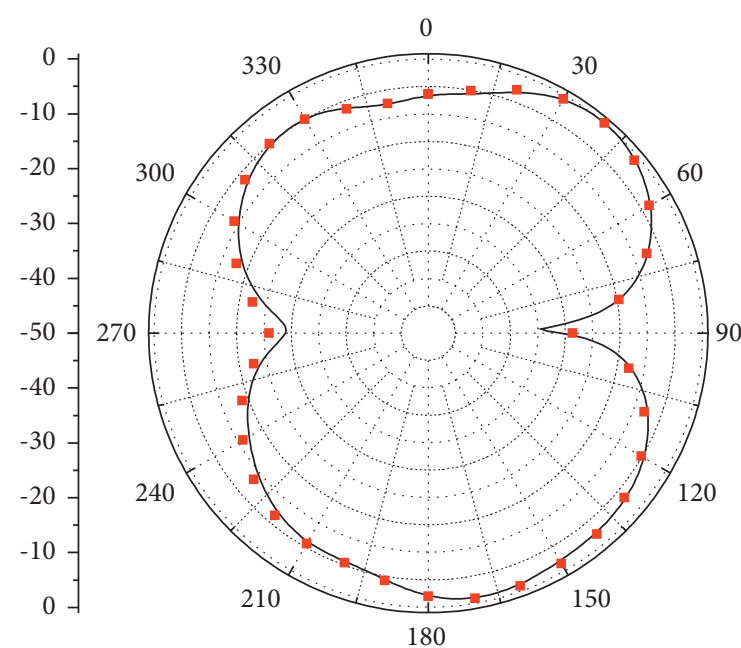

(b)

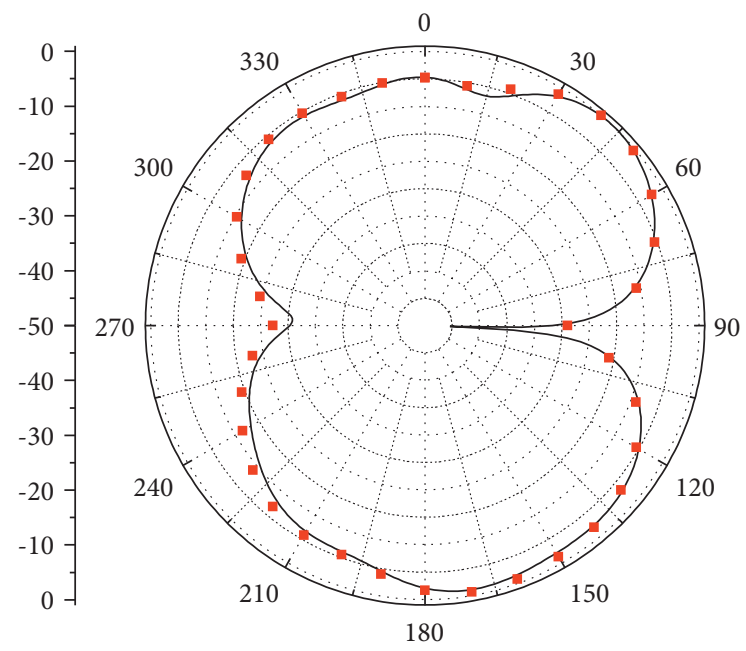

(c)

FIGURE 10: Simulated and measured radiation characteristics of the proposed array for the $y z$-plane at (a) $23 \mathrm{GHz}$, (b) $28 \mathrm{GHz}$, and (c) $29 \mathrm{GHz}$ (- simulated and $\mathbf{m}$ measured). 


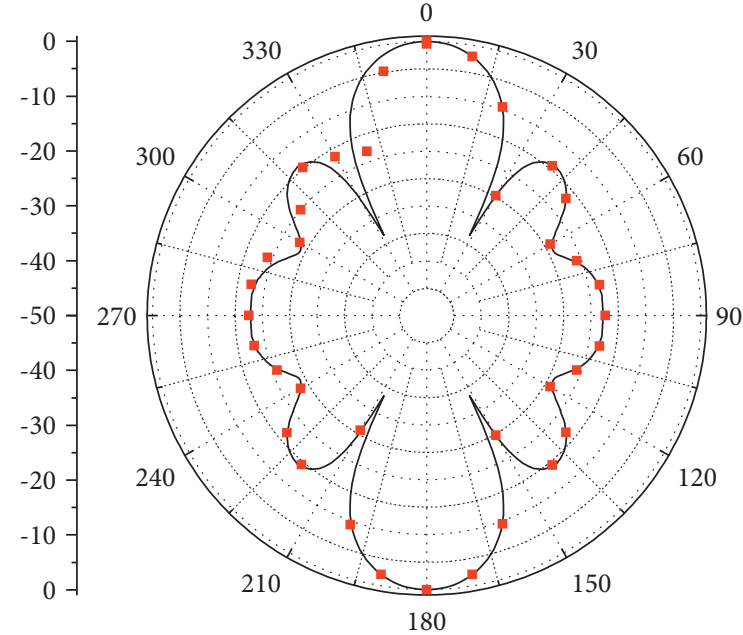

(a)

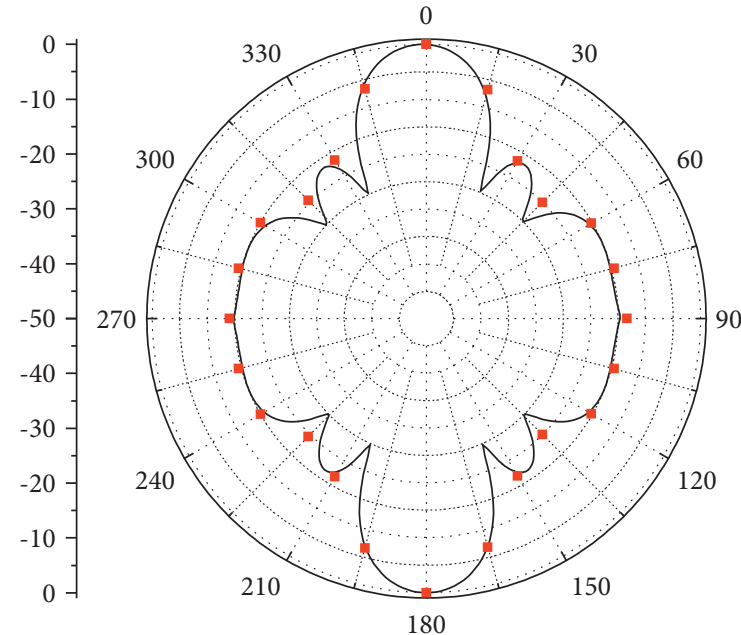

(b)

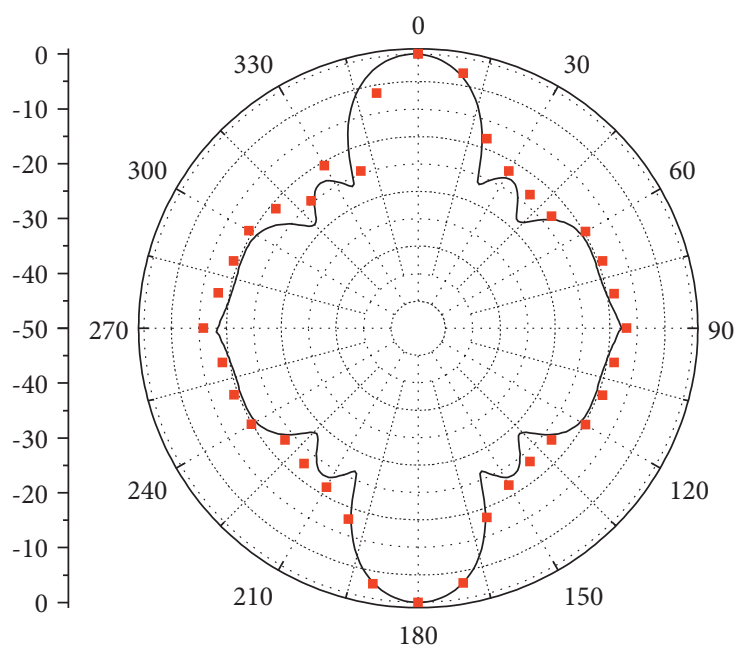

(c)

FIgURE 11: Simulated and measured radiation characteristics of the proposed array for the $x z$-plane at (a) $23 \mathrm{GHz},(\mathrm{b}) 28 \mathrm{GHz}$, and (c) $29 \mathrm{GHz}$ (- simulated and $\boldsymbol{m}$ measured).

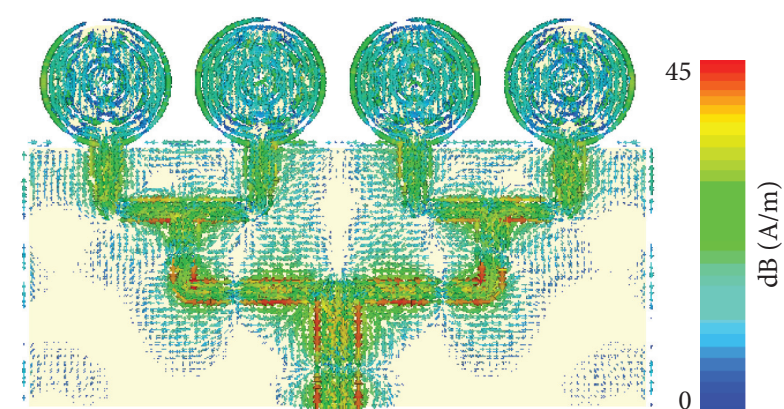

FIgURE 12: Surface current distribution for the proposed array.

is greater than $95 \%$ across the entire operating frequency band.

The radiation properties of the proposed array for the initial $(23 \mathrm{GHz})$, middle $(28 \mathrm{GHz})$, and end frequency $(29 \mathrm{GHz})$ are shown in Figures 10 and 11. From Figure 10, for the $y z$-plane, one can observe that the proposed array exhibits a typical eight-shaped radiated pattern for the frequency bands mentioned above. For the $x z$-plane, shown in Figure 11, highly directive dual-beam radiation properties are observed. In addition, a beamwidth of about $23^{\circ}$ is observed for $23 \mathrm{GHz}$, while for $28 \mathrm{GHz}$ and $29 \mathrm{GHz}$, it is $\approx 20^{\circ}$.

The simulated surface current distribution for the proposed array at $28 \mathrm{GHz}$ is depicted in Figure 12. It is observed that the current is uniformly distributed along the feeding network and between the array elements. A uniform amplitude distribution of the surface current led to achieving high gain and smaller beamwidth, which can clearly be observed from the results of Figures 9(a) and 11.

\section{Comparative Analysis}

Table 1 presents a comparison between the proposed array and previously presented literature. The designs presented in [8-10, 12-14] offered large bandwidth or high gain, but they have a large size compared to the presented design. On the contrary, the designs presented in [15-17] are compact, but 
TABLE 1: Comparison between the proposed array and previously published literature.

\begin{tabular}{|c|c|c|c|c|c|}
\hline Reference & Dimensions $\left(\mathrm{mm}^{2}\right)$ & Array elements & Bandwidth $(\mathrm{GHz})$ & Efficiency (\%) & Gain $(\mathrm{dBi})$ \\
\hline [8] & $45 \times 20$ & 4 & 10 & 85 & 12.15 \\
\hline [9] & $40 \times 15$ & 4 & 15.42 & 83 & 11.5 \\
\hline [10] & $40 \times 19.22$ & 4 & 4.63 & 85 & 11.24 \\
\hline [12] & $37.6 \times 14.3$ & 4 & 10.51 & 90 & 10.7 \\
\hline [13] & $32 \times 12$ & 4 & 3.76 & 80 & 10.12 \\
\hline [14] & $26 \times 40$ & 4 & 4.92 & - & 18 \\
\hline [18] & $34.1 \times 10$ & 8 & 27.7 & - & 10.8 \\
\hline [15] & $26.9 \times 18.5$ & 4 & 2.4 & 90 & 10.3 \\
\hline$[16]$ & $22 \times 20$ & 4 & 3.7 & 90 & 10.2 \\
\hline [17] & $24 \times 18.5$ & 4 & 3.7 & 94 & 11.5 \\
\hline This work & $28 \times 17.75$ & 4 & 6.4 & 95 & 10.7 \\
\hline
\end{tabular}

they suffer due to lower impedance bandwidth. Furthermore, the design presented in [18] offered extremely wide impedance bandwidth on the cost of increased array elements.

\section{Conclusion}

A $1 \times 4$ linear antenna array is designed for the $28 \mathrm{GHz}$ frequency band. The single element of the array comprises a rhombus-inscribed circular ring fractal patch radiator and a notch-loaded partial ground plane. The designed antenna element demonstrates a wide impedance bandwidth from 22.28 GHz to $33 \mathrm{GHz}$. A 4-way corporate feeding network is designed for the antenna array. From simulations as well as measurements, it is observed that the designed array resonates well in the band of interest and offers a peak gain and radiation efficiency of $10.7 \mathrm{dBi}$ and $95 \%$, respectively. One can also conclude from the presented results that the designed antenna array is a potential candidate for future high-speed $5 \mathrm{G}$ communication systems.

\section{Data Availability}

No data were used to support this study.

\section{Conflicts of Interest}

The authors declare that they have no conflicts of interest.

\section{References}

[1] Y. Wang, J. Li, L. Huang, Y. Jing, A. Georgakopoulos, and P. Demestichas, "5G mobile: spectrum broadening to higherfrequency bands to support high data rates," IEEE Vehicular Technology Magazine, vol. 9, no. 3, pp. 39-46, 2014.

[2] W. Roh, J.-Y. Seol, J. Park et al., "Millimeter-wave beamforming as an enabling technology for $5 \mathrm{G}$ cellular communications: theoretical feasibility and prototype results," IEEE Communications Magazine, vol. 52, no. 2, pp. 106-113, 2014.

[3] A. Osseiran, F. Boccardi, V. Braun et al., "Scenarios for 5G mobile and wireless communications: the vision of the metis project," IEEE Communications Magazine, vol. 52, no. 5, pp. 26-35, 2014.

[4] A. I. Sulyman, A. T. Nassar, M. K. Samimi, G. R. MacCartney, T. S. Rappaport, and A. Alsanie, "Radio propagation path loss models for 5G cellular networks in the $28 \mathrm{GHz}$ and $38 \mathrm{GHz}$ millimeter-wave bands," IEEE Communications Magazine, vol. 52, no. 9, pp. 78-86, 2014.

[5] S. Zhu, H. Liu, Z. Chen, and P. Wen, "A compact gain-enhanced vivaldi antenna array with suppressed mutual coupling for 5G mmwave application," IEEE Antennas and Wireless Propagation Letters, vol. 17, no. 5, pp. 776-779, 2018.

[6] P. Ramanujam, M. Ponnusamy, and K. Ramanujam, "A compact wide-bandwidth antipodal vivaldi antenna array with suppressed mutual coupling for $5 \mathrm{G} \mathrm{mm-wave} \mathrm{applica-}$ tions," AEU - International Journal of Electronics and Communications, vol. 133, Article ID 153668, 2021.

[7] C.-X. Mao, M. Khalily, P. Xiao, T. W. Brown, and S. Gao, "Planar sub-millimeter-wave array antenna with enhanced gain and reduced sidelobes for 5G broadcast applications," IEEE Transactions on Antennas and Propagation, vol. 67, no. 1, pp. 160-168, 2018.

[8] H. Ullah and F. A. Tahir, "A broadband wire hexagon antenna array for future $5 \mathrm{G}$ communications in $28 \mathrm{GHz}$ band," $\mathrm{Mi}$ crowave and Optical Technology Letters, vol. 61, no. 3, pp. 696-701, 2019.

[9] H. Ullah and F. A. Tahir, "Broadband planar antenna array for future 5G communication standards," IET Microwaves, Antennas \& Propagation, vol. 13, no. 15, pp. 2661-2668, 2019.

[10] H. Ullah and F. A. Tahir, "A wide-band rhombus monopole antenna array for millimeter wave applications," Microwave and Optical Technology Letters, vol. 62, no. 5, pp. 2111-2117, 2020.

[11] M. I. Khattak, A. Sohail, U. Khan, Z. Barki, and G. Witjaksono, "Elliptical slot circular patch antenna array with dual band behaviour for future 5G mobile communication networks," Progress In Electromagnetics Research C, vol. 89, pp. 133-147, 2019.

[12] H. Ullah and F. A. Tahir, "A high gain and wideband narrowbeam antenna for 5G millimeter-wave applications," IEEE Access, vol. 8, pp. 29430-29434, 2020.

[13] H. Ullah and F. A. Tahir, "A novel snowflake fractal antenna for dual-beam applications in $28 \mathrm{GHz}$ band," IEEE Access, vol. 8, pp. 19873-19879, 2020.

[14] Y. Q. Guo, Y. M. Pan, and S. Y. Zheng, "Design of series-fed, single-layer, and wideband millimeter-wave microstrip arrays," IEEE Transactions on Antennas and Propagation, vol. 68, no. 10, pp. 7017-7026, 2020.

[15] M. M. Kamal, S. Yang, S. H. Kiani et al., "A novel hook-shaped antenna operating at $28 \mathrm{GHz}$ for future $5 \mathrm{G}$ mmwave applications," Electronics, vol. 10, no. 6, p. 673, 2021.

[16] M. M. Kamal, S. Yang, S. H. Kiani et al., "Donut-shaped mmwave printed antenna array for 5G technology," Electronics, vol. 10, no. 12, Article ID 1415, 2021.

[17] S. H. Kiani, X. C. Ren, A. Bashir et al., "Square-framed T shape mmwave antenna array at $28 \mathrm{GHz}$ for future $5 \mathrm{G}$ devices," 
International Journal of Antennas and Propagation, vol. 2021, pp. 1-9, 2021.

[18] H. Wang, K. E. Kedze, and I. Park, "A high-gain and wideband series-fed angled printed dipole array antenna," IEEE Transactions on Antennas and Propagation, vol. 68, no. 7, pp. 5708-5713, 2020.

[19] A. Li and K.-M. Luk, "Millimeter-wave end-fire magnetoelectric dipole antenna and arrays with asymmetrical substrate integrated coaxial line feed," IEEE Open Journal of Antennas and Propagation, vol. 2, pp. 62-71, 2020.

[20] Q. Yang, S. Gao, Q. Luo et al., "Millimeter-wave dual-polarized differentially fed 2-D multibeam patch antenna array," IEEE Transactions on Antennas and Propagation, vol. 68, no. 10, pp. 7007-7016, 2020.

[21] Y. Cheng and Y. Dong, "Wideband circularly polarized planar antenna array for 5G millimeter-wave applications," IEEE Transactions on Antennas and Propagation, vol. 69, no. 5, pp. 2615-2627, 2020.

[22] G. Kumar and K. P. Ray, Broadband Microstrip Antennas, Artech House, London, 2003. 